\title{
Multiple Domains of the Tobacco mosaic virus p126 Protein Can Independently Suppress Local and Systemic RNA Silencing
}

\author{
Li-Ya Wang, ${ }^{1,2}$ Shih-Shun Lin, ${ }^{3}$ Ting-Hsuan Hung, ${ }^{1,4}$ Tsai-Kun Li, ${ }^{2}$ Nai-Chun Lin,,${ }^{4,5}$ and Tang-Long Shen ${ }^{1}$ \\ ${ }^{1}$ Department of Plant Pathology and Microbiology, College of Bioresources and Agriculture, National Taiwan University, \\ Taipei, Taiwan; ${ }^{2}$ Graduate Institute of Microbiology, National Taiwan University Medical School, Taipei, Taiwan; and ${ }^{3}$ Institute \\ of Biotechnology, ${ }^{4}$ Program in Plant Medicine, and ${ }^{5}$ Department of Agricultural Chemistry, College of Bioresources and \\ Agriculture, National Taiwan University, Taipei, Taiwan
}

Submitted 7 June 2011. Accepted 11 January 2012.

\begin{abstract}
Small RNA-mediated RNA silencing is a widespread antiviral mechanism in plants and other organisms. Many viruses encode suppressors of RNA silencing for counterdefense. The p126 protein encoded by Tobacco mosaic virus (TMV) has been reported to be a suppressor of RNA silencing but the mechanism of its function remains unclear. This protein is unique among the known plant viral silencing suppressors because of its large size and multiple domains. Here, we report that the methyltransferase, helicase, and nonconserved region II (NONII) of p126 each has silencing-suppressor function. The silencing-suppression activities of methyltransferase and helicase can be uncoupled from their enzyme activities. Specific amino acids in NONII previously shown to be crucial for viral accumulation and symptom development are also crucial for silencing suppression. These results suggest that some viral proteins have evolved to possess modular structural domains that can independently interfere with host silencing, and that this may be an effective mechanism of increasing the robustness of a virus.
\end{abstract}

RNA silencing triggered by 21- to 24-nucleotide small-interfering RNAs (siRNAs) is a potent antiviral defense mechanism in plants and other organisms. In a general scheme, siRNAs are generated from double-stranded RNA (dsRNA) precursors, such as the replication intermediates of viral RNAs, by an RNase III-like nuclease called dicer or dicer-like. The siRNAs are incorporated into argonaute proteins of the RNA-induced silencing complex (RISC) to guide sequence-specific cleavage of viral RNAs (Ding and Voinnet 2007). In plants, the RNA silencing signal spreads from cell to cell and from organ to organ to elicit systemic viral defense responses (Ding and Voinnet 2007).

To counteract the anti-viral effect of host RNA silencing, many plant viruses encode suppressors of RNA silencing (VSR) (Ding and Voinnet 2007). Examples include HC-Pro from Potato virus $Y$, P1/HC-Pro from Tobacco etch potyvirus, $2 \mathrm{~b}$ from Cucumber mosaic virus, $\mathrm{p} 25$ from Potato virus $X, \mathrm{p} 19$ from Tomato bushy stunt virus, and $\mathrm{p} 126$ from Tobacco mosaic virus (TMV) (Anandalakshmi et al. 1998; Brigneti et al. 1998; Ding et al. 2004; Kasschau and Carrington 1998; Voinnet et al. 1999; Voinnet et al. 2000). VSR can interfere with different

Corresponding author: T.-L. Shen; Telephone: +886-2-3366-4998; Fax: +886-2-2363-6490; E-mail: shentl@ntu.edu.tw steps of an RNA silencing pathway (Giner et al. 2010; Pantaleo et al. 2007; Martin-Hernandez and Baulcombe 2008). Their actions involve two general mechanisms: sequestering siRNAs to interfere with their entry into RISC or inhibiting the function of RNA-silencing pathway proteins (Jin and Zhu 2010).

In addition to its role in suppressing RNA silencing (Ding et al. 2004), TMV p126 plays an important role in viral RNA genome replication and viral cell-to-cell movement (Ding et al. 2004; Liu et al. 2005). One possible mechanism underlying p126 suppression of silencing is size-selective binding of siRNAs (Merai et al. 2006). Prominent features of p126, among the known VSR, are its large size (126 kDa) and multiple domains. These domains include the N-terminal methyltransferase (MET), two nonconserved regions (NONI and NONII), and one helicase (HEL) (Kadare and Haenni 1997). The MET domain is similar to $S$-adenosylmethionine (SAM)binding proteins in the regulation of methyl group transfer (Koonin and Dolja 1993). The MET domain is important for viral cell-to-cell movement (Knapp et al. 2005). It also interacts with plant translation elongation factor 1A (Yamaji et al. 2006). TMV p126 also exhibits guanylyltransferase activity in vitro and catalyzes the methyl group covalent-conjugation on GTP to facilitate the formation of an $\mathrm{m}^{7}$ GMP-p126 complex (Merits et al. 1999). The HEL domain is crucial for viral survival or temperature-sensitive replication (Goregaoker et al. 2001). It is capable of hydrolyzing ATP, binding dsRNA as well as single-stranded RNA in an ATP-dependent manner, and unwinding RNA duplexes (Goregaoker and Culver 2003). The biological functions of NONI and NONII remain to be understood but several mutations in these regions affect symptom development (Bao et al. 1996; Holt et al. 1990; Shintaku et al. 1996). Given the multidomain nature of p126, a mechanistic question, which is of great importance to understand the evolution of viral counter-defense strategies, is whether one or more of its domains carries out the RNA silencing-suppression function.

Here, we report that the MET, HEL, and NONII of p126 each has silencing-suppressor function. The silencing-suppression activities of MET and HEL can be uncoupled from their enzyme activities. Specific amino acids in NONII previously shown to be crucial for viral accumulation and symptom development are also crucial for silencing suppression. These results suggest that some viral proteins have evolved to possess modular structural domains that can independently interfere with host silencing, and that this may be an effective mechanism of increasing the robustness of a virus. 


\section{RESULTS}

p126 is a strong suppressor of RNA silencing suppression.

To establish the role of TMV p126 in RNA silencing suppression (Ding et al. 2004) for further studies in our experimental system, we first tested silencing suppression by TMV infection. To this end, we used transgenic Nicotiana benthamiana line 16c expressing green fluorescent protein (GFP) (Ruiz et al. 1998; Voinnet and Baulcombe 1997). Infiltration of a leaf with a modified Agrobacterium tumefaciens strain, C58C1, that harbors pBin61-35S-GFP followed by inoculation of the same leaf with water led to an initial increase in GFP fluorescence, above that resulted from the expression of the transgene, that gradually faded out at 11 days postinfiltration (dpi). The disappearance of GFP fluorescence was indicative of silenced expression of the transgene GFP induced by the ectopic GFP expression (Fig. 1A, left panel). However, infiltration of a leaf with pBin61-35S-GFP followed by inoculation of the same leaf with RNA transcripts of TMV led to persistent presence of GFP fluorescence during the same experimental period (Fig. 1A, right panel). These results confirmed that TMV infection resulted in suppression of host RNA silencing. To further establish the role of p126 in the suppression of RNA silencing as shown in $N$. tabacum (Ding et al. 2004; Harries et al. 2008), we generated a pBin61-p126 construct containing a myc-6X His tag at the C-terminus of the p126 under the control of the Cauliflower mosaic virus-35S promoter. Infiltration of $N$. benthamiana line 16c with pBin61-35S-GFP alone resulted in initial GFP fluorescence that started to fade out at $8 \mathrm{dpi}$ (Fig. 1B, left panel), along with reduced accumulation of GFP mRNA (Fig. 1D). In contrast, co-infiltration of pBin61-p126 with pBin61-35S-GFP led to retention of GFP fluorescence (Fig. 1B, left panel) along with elevated GFP mRNA levels during the same experimental period (Fig. 1D). Expression of p126 was confirmed by Western blotting (Fig. 1B, right panel). Thus, p126 was able to suppress RNA silencing. Furthermore, p126 was capable of suppressing systemic RNA silencing (Fig. 1C). We concluded that the TMV p126 protein is an efficient suppressor of local and systemic RNA silencing.

\section{The multiple p126 domains each have local RNA silencing-suppression activity.}

To determine whether any of the p126 domains were able to exert RNA silencing-suppression activity in the absence of the other domains, we generated four DNA constructs expressing each of the four domains of p126 (i.e., the MET, NONI, NONII, and HEL) containing a C-terminal myc-tag in the pBA binary vector (Fig. 2A). The leaves of $N$. benthamiana line $16 \mathrm{c}$ were infiltrated with Agrobacterium sp. strain ABI (Aoyama and Chua 1997) engineered to carry each of these constructs. Western blots with anti-myc antibodies verified in planta expression of the respective p126 domains (Fig. 2B).

To test the RNA silencing-suppression effects of these p126 domains individually, we co-infiltrated leaves of $N$. benthamiana line $16 \mathrm{c}$ with pBA-35S-GFP (thereafter called pBAGFP for simplicity) and pBA-p126, pBA-MET, pBA-NONI, pBA-NONII, or pBA-HEL. Co-infiltration of pBA-GFP with pBA-p126 or with pBA served as positive and negative controls, respectively. GFP fluorescence declined when pBA-GFP was co-infiltrated with pBA vector or pBA-NONI at 4 dpi (Fig. $3 \mathrm{~A})$ but increased when pBA-GFP was co-infiltrated with pBA-MET, pBA-NONII or pBA-HEL. The increase was higher in the presence of NONII or HEL than in the presence of MET. The higher GFP fluorescence was directly correlated with higher accumulation levels of GFP mRNAs and lower accumulation of GFP siRNAs (Fig. 3B). The increase in GFP mRNA levels was statistically significant when pBA-GFP was

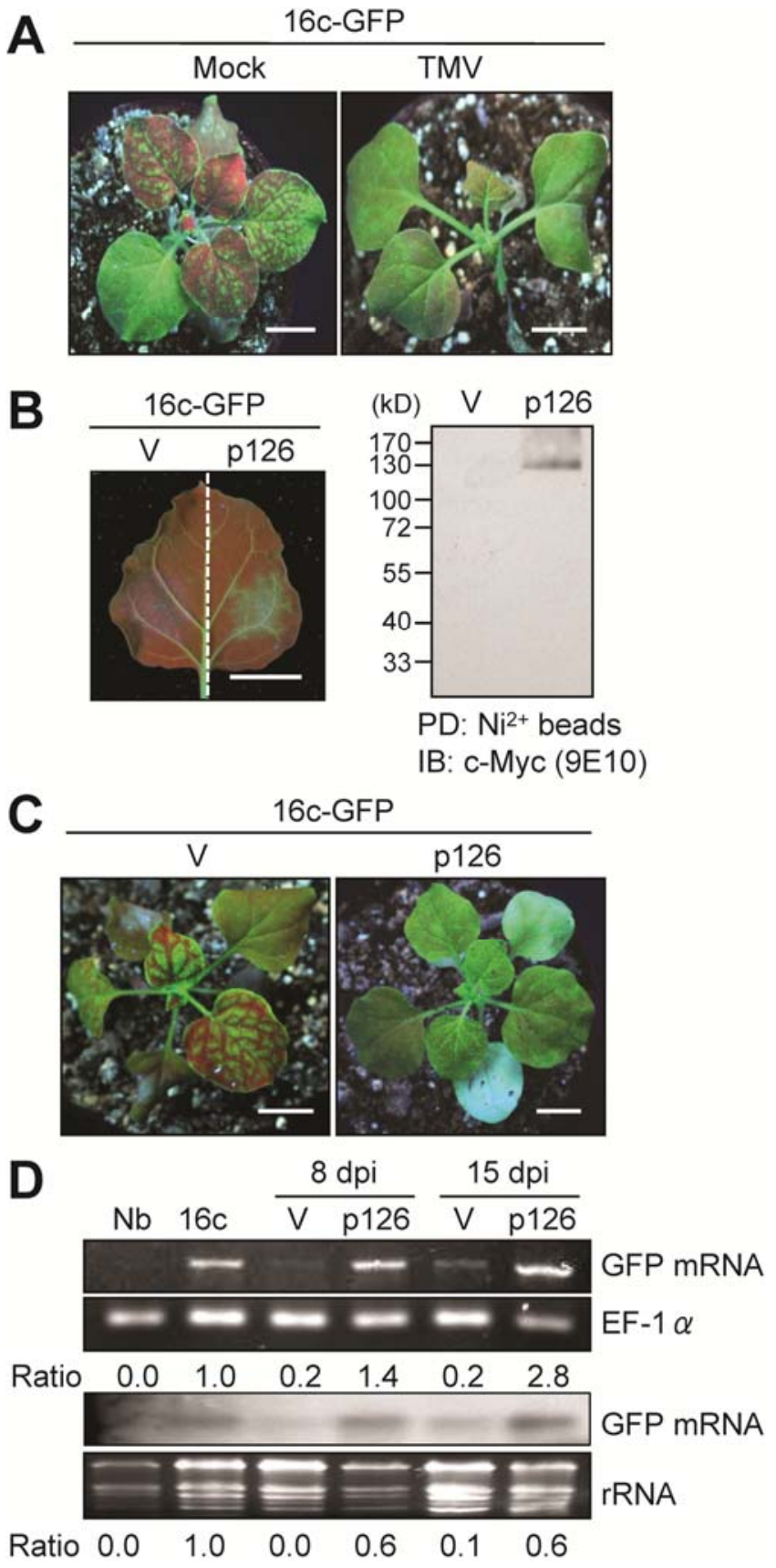

Fig. 1. Tobacco mosaic virus (TMV) p126 protein suppresses local and systemic RNA silencing in Nicotiana benthamiana. A, TMV suppresses RNA silencing in $N$. benthamiana line 16c. Silencing of green fluorescent protein (GFP) expression was induced by infiltrating a leaf with a modified Agrobacterium strain harboring pBin61-35S-GFP. Left panel shows silenced expression of GFP in a plant infiltrated with pBin61-35S-GFP followed by mock inoculation with water at 11 days postinoculation (dpi). Right panel shows strong GFP fluorescence, as a result of suppressed silencing, in a plant infiltrated with pBin61-35S-GFP followed by inoculation with TMV at 11 dpi. B, A 16c plant leaf infiltrated with an Agrobacterium sp. expressing pBin61-35S-GFP (GFP) in combination with pBin61 binary vector (V; left side) or with pBin61-p126 (p126, right side) at 8 dpi. Note suppression of local silencing of GFP expression by 126 . The right panel shows Western blot to confirm p126 expression in the infiltrated leaf patch. C, Similar experiments as shown in B, showing p126 suppression of systemic silencing of GFP (right panel) compared with vector control (left panel). D, Reverse-transcriptase polymerase chain reaction (upper panel) and Northern blot (bottom panel) show higher accumulation of GFP mRNA in p126-infiltrated leaf patches than in empty vector-infiltrated patches. The GFP mRNA levels in the $16 \mathrm{c}$ plants are set to 1.0 and those from the treated leaf tissues are expressed as relative values. Data were average of at least three independent experiments. Scale bars in A, B, and C represent $2 \mathrm{~cm}$. 
co-infiltrated with p126, MET, NONII, or HEL compared with pBA vector (Fig. 3C). Together, these data indicate that the MET, NONII, and HEL domains each has local RNA silencing-suppression activity. The specific association of such activity with each of these domains is further supported by the lack of such activity by NONI.

The p126 MET, NONII, and HEL domains each interfere with systemic silencing.

When we examined the systemic leaves of $N$. benthamiana line $16 \mathrm{c}$ that were co-infiltrated with pBA-GFP and pBA (negative control), pBA-p126 (positive control), pBA-MET, pBANONII, pBA-NONI, or pBA-HEL, we found that MET, NONII, and HEL (but not NONI) could interfere with systemic RNA silencing as p126, the positive control, did (Fig. 4A). Statistical analysis of GFP fluorescence intensities showed the suppression efficiencies to be $85,73,59,52$, and $0 \%$ for p126, NONII, MET, HEL, and NONI, respectively (Table 1). The GFP fluorescence intensities were positively correlated with the GFP mRNA levels and negatively correlated with the GFP siRNA levels in the systemic leaves (Fig. 4B). The increase in GFP mRNA levels was statistically significant (Fig. 4C). These data indicate that the MET, NONII, and HEL domains of p126 can each independently interfere with systemic RNA silencing, albeit to different degrees.

The RNA silencing-suppression function of MET or HEL is uncoupled from their enzymatic activities.

An interesting mechanistic question is whether the enzymatic activities of MET and HEL are crucial for their silencingsuppression function. To address this question, we generated enzymatically inactive forms of MEL and HEL by site-directed mutagenesis. Specifically, histidine-81 and threonine-840 (numbered based on the full-length p126) was each substituted by alanine (Fig. 2, MET* and HEL*), resulting in inactivation of MEL and HEL enzymatic activities, respectively (Erickson et al. 1999; Pelle and Murphy 1993). These mutant domains were expressed in $N$. benthamiana line $16 \mathrm{c}$ by agroinfiltration, as confirmed by Western blotting (Fig. 2C). They retained full capacities to suppress local and systemic silencing (Table 2), as shown by elevated levels of GFP fluorescence (Figs. 5A and 6A) and mRNA (Figs. 5B and $\mathrm{C}$ and $6 \mathrm{~B}$ and $\mathrm{C}$ ). These are negatively correlated with the levels of GFP siRNAs (Figs. 5B and $6 \mathrm{~B})$. Thus, the RNA silencing-suppression function of these domains is likely attributed to a novel mechanism distinct from their enzymatic activities.

\section{Specific amino acids in NONII that are critical for symptom expression are also critical for RNA silencing suppression.}

The specific function of NONII in viral infection is unclear but certain amino acids within this domain are essential for viral accumulation and symptom development (Bao et al. 1996; Derrick 1997; Ding et al. 2004; Holt et al. 1990; Lewandowski and Dawson, 1993; Shintaku et al. 1996). These observations prompted us to test whether the RNA silencing-suppression function of NONII plays a role in symptom development. To this end, we generated a triple mutant (Fig. 2, NONII*) in which three amino acids (E602K, K669R, and A747T) were simultaneously mutated. NONII* was expressed in $N$. benthamiana line $16 \mathrm{c}$ by agroinfiltration (Table 2), as confirmed by Western blotting (Fig. 2C), and had a dramatic reduction in the RNA silencing-suppression capacity (Figs. 5 and 6). The reduced GFP fluorescence was correlated with reduced GFP

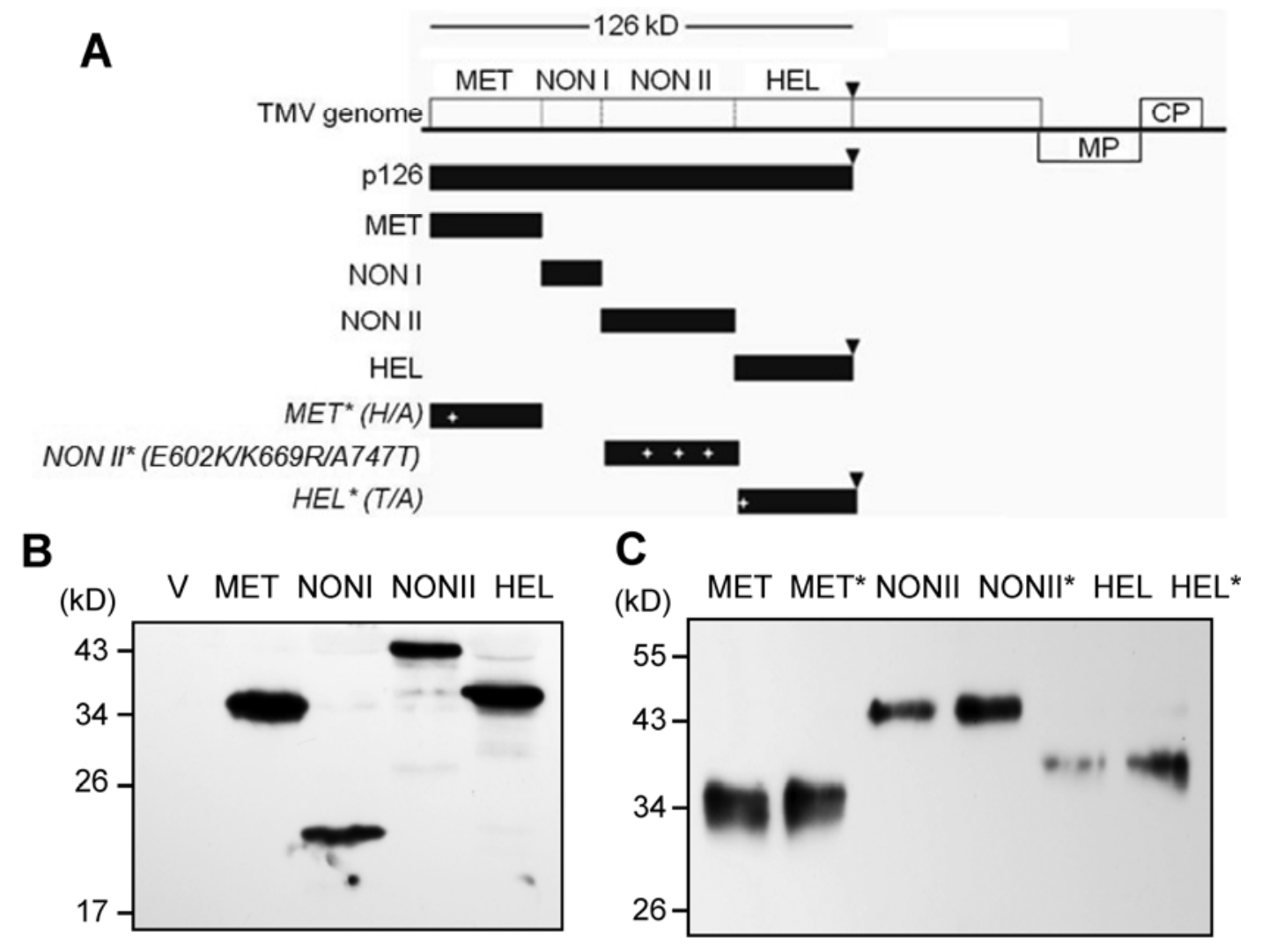

Fig. 2. DNA constructs and in planta expression of various p126 domains and domain mutants. A, Schematic representation of the Tobacco mosaic virus (TMV) genome organization, expression constructs for each of the p126 domains, and domain mutants. The endogenous stop codon (TAG) is indicated with a black triangle $(\boldsymbol{\nabla})$. White stars in the black bar indicate the point mutation sites introduced. B, Western blots showing expression of p126 domains in agroinfiltrated Nicotiana benthamiana line 16c. C, Western blots showing expression of p126 domain mutants in agroinfiltrated $N$. benthamiana line $16 \mathrm{c}$. 
mRNA and increased GFP siRNA levels. We also generated single mutants of NONII and found that mutants E602K and A747T still exhibited partial effects on RNA silencing suppression and mutant K669R retained full suppression function (data not shown). These results suggest a correlation between the RNA silencing-suppression and symptom-eliciting functions of NONII.

\section{A}
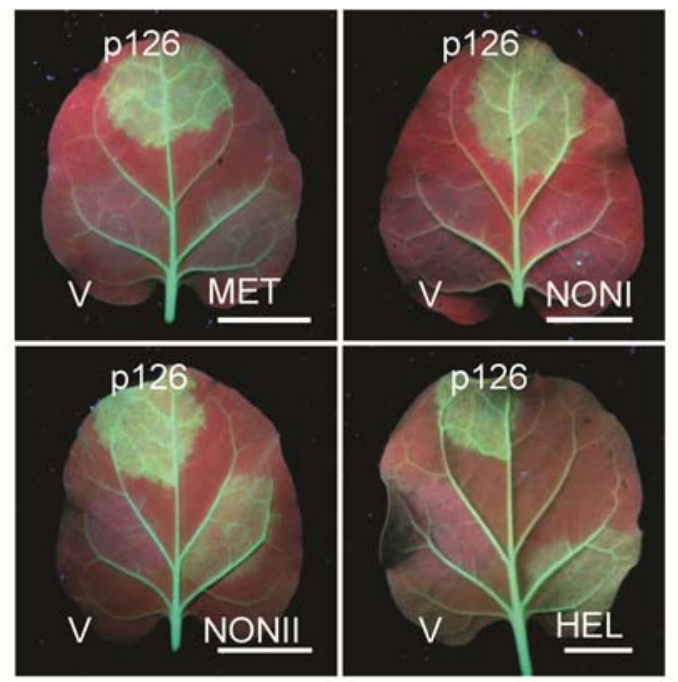

B
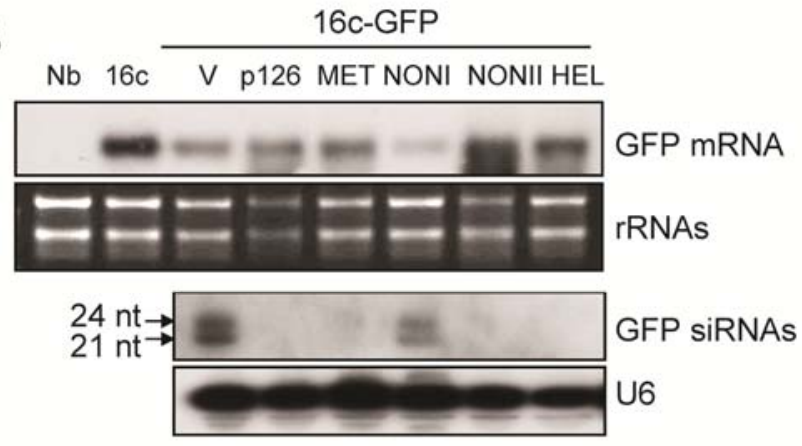

C

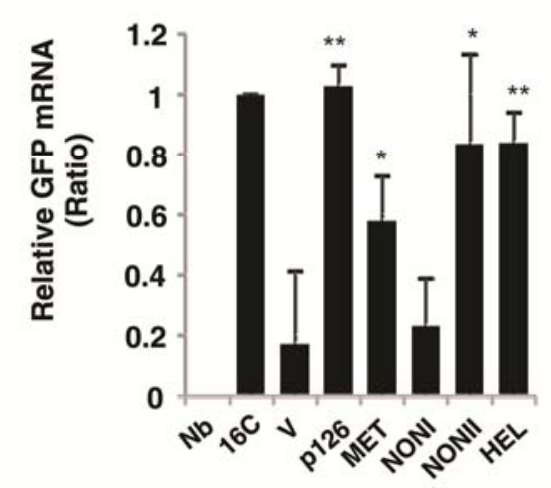

Fig. 3. Local RNA silencing-suppression activities of different p126 domains in Nicotiana benthamiana line 16c at 4 days postinoculation. A, Leaves were co-agroinfiltrated with pBA-green fluorescent protein (GFP) together with pBA empty vector (V), p126, methyltransferase (MET), two nonconserved regions (NONI and NONII), or one helicase (HEL). White scale bars indicate $2 \mathrm{~cm}$. B, Northern blots showing accumulation levels of GFP mRNA and GFP small-interfering RNA (siRNA) in leaf patches infiltrated with various constructs. The GFP mRNA and siRNA levels in the $16 \mathrm{c}$ plants are set to 1.0 and those from the treated leaf tissues are expressed as relative values. $\mathrm{Nb}$ indicates samples from nontransgenic and noninfiltrated plants. rRNA and U6 RNA lanes serve as loading controls. C, Average levels (plus standard deviations) of GFP mRNA, based on data from three biological replicates, that were normalized to the endogenous GFP mRNA of $16 \mathrm{c}$ line. Statistical differences between p126 domains and vector clone are shown at $P<0.05$ and 0.01 levels (* and $* *$, respectively).
To further test this correlation, we inoculated $N$. tabacum with the TMV mild strain MII-16 (Rast 1972) followed by infiltration with Agrobacterium spp. expressing NONII or NONII* derived from the severe strain TMV-U1. Plants dis-

A
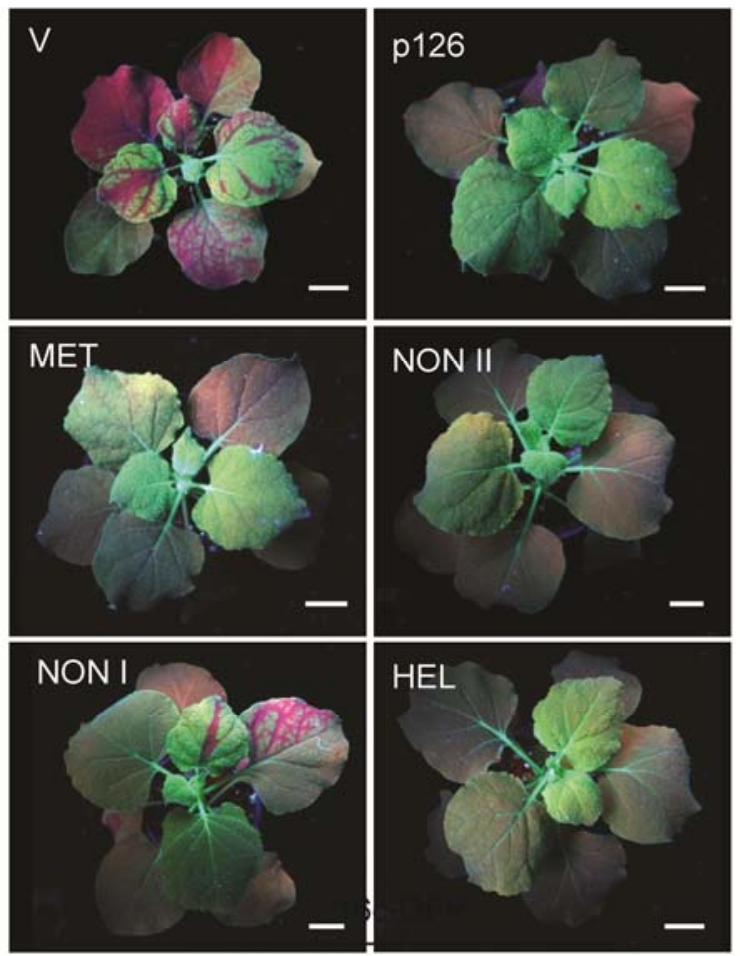

B

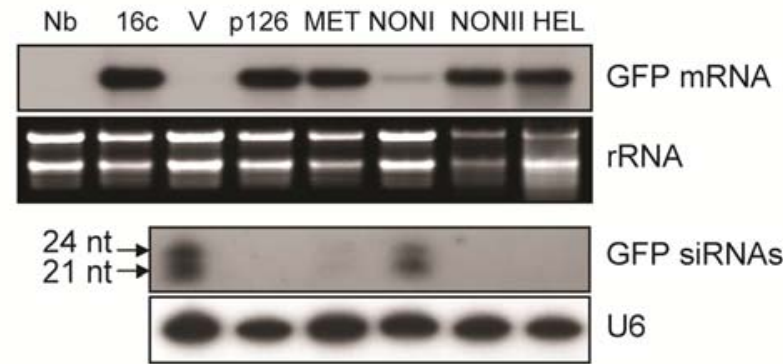

C

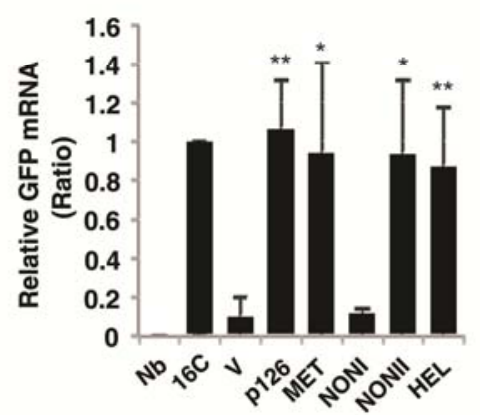

Fig. 4. Systemic RNA silencing-suppression activities of different p126 domains in Nicotiana benthamiana line 16c at 18 days postinoculation. A, Systemic leaves from plants co-infiltrated with pBA-green fluorescent protein (GFP) and pBA empty vector (V), p126, methyltransferase (MET), two nonconserved regions (NONI and NONII), or one helicase (HEL). White scale bars indicate $2 \mathrm{~cm}$. B, Northern blots showing accumulation levels of GFP mRNA and GFP small-interfering RNA (siRNA) in systemic leaves. The GFP mRNA and siRNA levels in the 16c plants are set to 1.0 and those from the leaves of treated plants are expressed as relative values. $\mathrm{Nb}$ indicates samples from nontransgenic and noninfiltrated plants. rRNA and U6 RNA lanes serve as loading controls. C, Average levels (plus standard deviations) of GFP mRNA, based on data from three biological replicates, that were normalized to the endogenous GFP mRNA of $16 \mathrm{c}$ line. Statistical differences between p126 domains and vector clone are shown at $P<0.05$ and 0.01 levels (* and **, respectively). 
played severe wrinkling and mosaic symptoms when infected by MII-16 in the presence of ectopically expressed TMV-U1 NONII (Fig. 7Aa), in contrast to the lack of such symptoms in plants infected by MII-16 alone or in the presence of ectopically expressed TMV U1 NONII* (Fig. 7Ab). Northern blots showed that NONII as well as p126, but not NONII*, enhanced MII-16 accumulation in systemic leaves (Fig. 7B). It should be noted that MII-16 alone has the capability to suppress RNA silencing (data not shown), which may derive from the activities of MEL or HEL. The NONII of MII-16 bears some amino acid substitutions compared with the NONII of TMV-U1, including E602G and K669R, that affect symptom development or RNA silencing suppression (data not shown).

\section{DISCUSSION}

Most plant VSR known to date are dedicated to suppression of host RNA silencing (Diaz-Pendon and Ding 2008). The TMV p126 is unique among the VSR because of its large size and multifunctional domains. Our results demonstrate that the MEL, HEL, and NONII domains of p126 each have RNA silencing-suppression activities, albeit at different degrees. The basis for the differences may be further explored when the mechanisms underlying the suppression activity of each domain become clear.

The mechanisms of MEL and HEL function in silencing suppression are unclear but some possibilities may be discussed by considering the involvement of methyltransferase and HEL activities in RNA silencing in general. For example, siRNAs and microRNAs are methylated by HUA ENHANCER 1 (HEN1) before incorporation into RISC ( $\mathrm{Li}$ et al. 2005; Yu et al. 2005). HEN1 is an SAM-binding methyl transferase that methylates the $2^{\prime}$ hydroxyl termini of riboses at the $3^{\prime}$ terminal nucleotide of each strand of a small RNA duplex, a reaction that appears to be unique for the plant kingdom (Boutet et al. 2003; Park et al. 2002). Recently, DmHen1, an RNA methyltransferase, was found to modify Piwi-interacting RNA and single-stranded siRNAs in Drosophila melanogaster (Horwich et al. 2007). Presumably, the methylation protects small RNAs from degradation and polyuridylation (Vaucheret 2006). Furthermore, methyltransferase was necessary for cell-to-cell movement of viruses through association with the RNA-binding subunit of eIF-3 (Knapp et al. 2005; Osman and Buck 1997; Taylor and Carr 2000). Our data show that a mutation in MET predicted to disrupt its enzyme activity does not affect its RNA silencing-suppression function. It is possible that the mutant MET as well as the wild-type MET can compete with HEN1 by binding siRNAs, though not methylating them, to prevent their loading into RISC, thereby suppressing RNA silencing. It is also possible that MET functions in a different mechanism to suppress silencing.

Table 1. Suppression of systemic RNA silencing by Tobacco mosaic virus p126 and its truncated domains

\begin{tabular}{lccc}
\hline $\begin{array}{l}\text { Constructs } \\
\text { infiltrated }\end{array}$ & $\begin{array}{c}\text { Number of } \\
\text { plants } \\
\text { infiltrated }\end{array}$ & $\begin{array}{c}\text { Number of plants } \\
\text { showing systemic } \\
\text { silencing suppression }\end{array}$ & $\begin{array}{c}\text { Systemic } \\
\text { silencing } \\
\text { suppression (\%) }\end{array}$ \\
\hline GFP + vector & 20 & 0 & 0 \\
GFP + p126 & 27 & 23 & 85 \\
GFP + MET & 22 & 13 & 59 \\
GFP + NONI & 22 & 0 & 0 \\
GFP + NONII & 22 & 16 & 73 \\
GFP + HEL & 21 & 11 & 52 \\
GFP + AC2 & 6 & 5 & 83 \\
GFP + 2b & 4 & 4 & 100
\end{tabular}

${ }^{\mathrm{a}} \mathrm{GFP}=$ green fluorescent protein, MET $=$ methyltransferase, NONI and NONII $=$ two nonconserved regions, and HEL $=$ helicase .
HEL activities have been implicated in the virus-induced gene silencing pathway, in which double-stranded viral siRNAs are unwound by an ATP-dependent RNA HEL prior to being incorporated into RISC (Voinnet 2005). Moreover, in Arabidopsis thaliana, SDE3, which possesses RNA HEL activities, is required for the synthesis of secondary siRNAs (Dalmay et al. 2001; Vaistij et al. 2002). It has also been demonstrated that an RNA HEL, like HelF, could act as a suppressor of RNA silencing (Popova et al. 2006). The mechanisms underlying the opposing effects of these HEL on RNA silencing are not understood. It may be speculated that the p126 HEL binds but does not unwind duplexes of siRNAs, thereby preventing the assembly of an active RISC as a means to suppress silencing.

We found that specific amino acids in NONII that are crucial for TMV accumulation and symptom development are also critical for suppression of RNA silencing. The correlation between viral accumulation or symptom development and RNA silencing suppression is further supported by the finding that presence of TMV-U1 NONII (but not the silencing suppression mutant NONII*) enhances symptom development in tobacco infected by the mild strain TMV MUII-16. However, it remains to be understood how ectopic expression of NONII, as well as p126, in the MII-16-inoculated leaves enhanced viral accumulation in systemic leaves and disease symptoms. Because of the nonconserved nature of NONII, our findings raise the interesting possibility that viral strain-specific silencing-suppression activities of NONII are an underlying basis for enhanced viral accumulation and symptom development. The importance of NONII for viral infection is also underscored by the observation that NONI has no silencing-suppression activities. Thus, further studies on the nonconserved regions may provide new insights into their functions in virus-host interactions.

The presence of multiple domains in a viral protein for RNA silencing suppression may enhance the evolutionary robustness of a virus. First, the presence of multiple domains ensures that the virus does not completely lose silencing-suppression capacity if a domain is lost through mutations. Second, the multiple domains may act synergistically to enhance the counter-defense capacity of a virus, especially if different domains target different components or steps of the host RNA silencing pathway. Further studies on the specific mechanisms of silencing suppression by the MEL, HEL, and NONII domains of p126 should allow a test of these possibilities.

\section{MATERIALS AND METHODS}

\section{Plant material and growth conditions.}

Transgenic N. benthamiana line 16c (Voinnet and Baulcombe 1997; Ruiz et al. 1998) was obtained from D. Baulcombe (University of Cambridge, U.K.). All plants were grown in soil. TMV-U1 or MII-16 strains were kindly provided by H.-H. Yeh (National Taiwan University, Taiwan). Virus-infected plants

Table 2. Suppression of systemic silencing by the Tobacco mosaic virus p126 domain mutants

\begin{tabular}{lccc}
\hline Construct $^{\mathrm{a}}$ & $\begin{array}{c}\text { Number of } \\
\text { plants } \\
\text { infiltrated }\end{array}$ & $\begin{array}{c}\text { Number of plants } \\
\text { showing systemic } \\
\text { silencing suppression }\end{array}$ & $\begin{array}{c}\text { Systemic } \\
\text { silencing } \\
\text { suppression (\%) }\end{array}$ \\
\hline GFP + vector & 20 & 0 & 0 \\
GFP + p126 & 27 & 23 & 85 \\
GFP + MET & 10 & 6 & 60 \\
GFP + NONII* & 12 & 1 & 8 \\
GFP + HEL & 12 & 4 & 33 \\
\hline
\end{tabular}

${ }^{\mathrm{a}} \mathrm{GFP}=$ green fluorescent protein, MET = methyltransferase, NONI and NONII = two nonconserved regions, and HEL = helicase. 
were maintained in a growth chamber under a cycle of $16 \mathrm{~h}$ of light and $8 \mathrm{~h}$ of darkness at $24^{\circ} \mathrm{C}$.

\section{Plasmid constructs.}

All constructs used in this study are shown schematically in Figure 2A. Briefly, the DNA inserts of p126 and its various mutants were polymerase chain reaction (PCR) amplified from pUC18-TMV-U1 (Dawson et al. 1986) in a Mycycler thermal cycle (Bio-Rad, Singapore). The primers used were 126-5' and 126-3' for p126, MET-5' and MET-3' for MET, NONI-5' and NONI-3' for NONI, NONII-5' and NONII-3' for NONII, and HEL-5' and HEL-3' for HEL. The primers used for generating the mutants are listed in Table 3 . All of the $5^{\prime}$ and $3^{\prime}$ primers contain one NotI and one XhoI restriction site, respectively. PCR was used to generate various mutants. The resulting PCR products were first digested with NotI and XhoI and then ligated into the NotI/XhoI site of pcDNA3.1/myc- 6xHis A expression vector (Invitrogen, Carlsbad, CA, U.S.A.) at $16^{\circ} \mathrm{C}$ overnight. The fusion constructs from this vector were finally excised by digestion with EcoRV and PmeI and subcloned into pBA binary vector (Zhang et al. 2005) at the BamHI site filled in by T4 DNA polymerase. All pBA constructs were used to transform Agrobacterium tumefaciens ABI by electroporation. Positive transformants were selected by PCR.

\section{Agrobacterial growth and leaf infiltration.}

The recombinant A. tumefaciens strains bearing the constructs described above or pBin61-35S-GFP (Haseloff et al. 1997) were grown overnight at $28^{\circ} \mathrm{C}$ in Luria-Bertani (LB) medium supplemented with antibiotics for strain selection
A

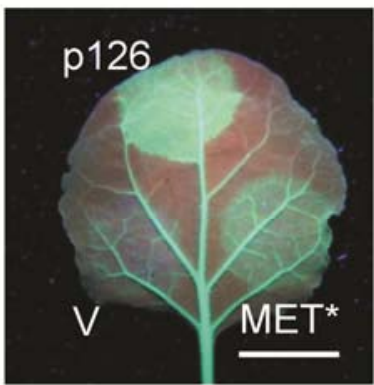

B

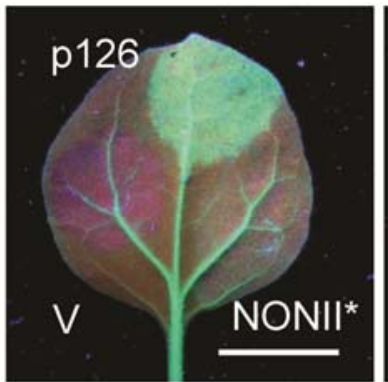

16c-GFP

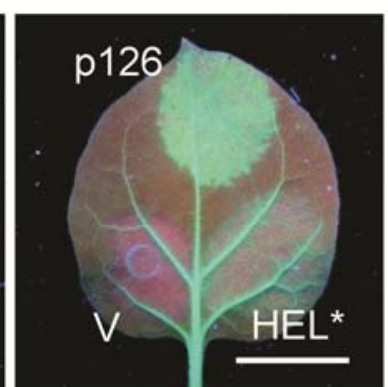

$\mathrm{Nb} \quad 16 \mathrm{c} \vee \mathrm{p} 126 \mathrm{MET}$ MET* NONII NONII* HEL HEL*

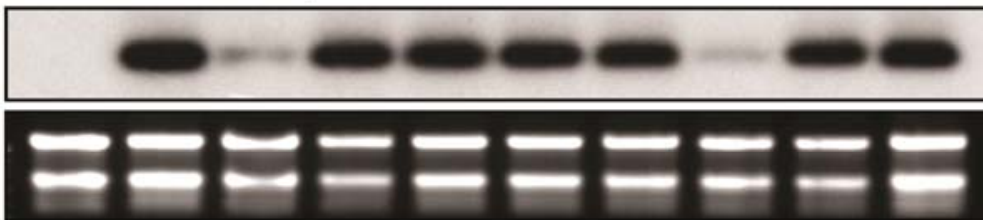

GFP mRNA

rRNA

$24 \mathrm{nt}$

$21 \mathrm{nt} \rightarrow$

.

$*$

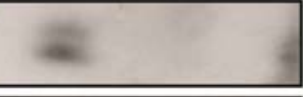

GFP siRNA

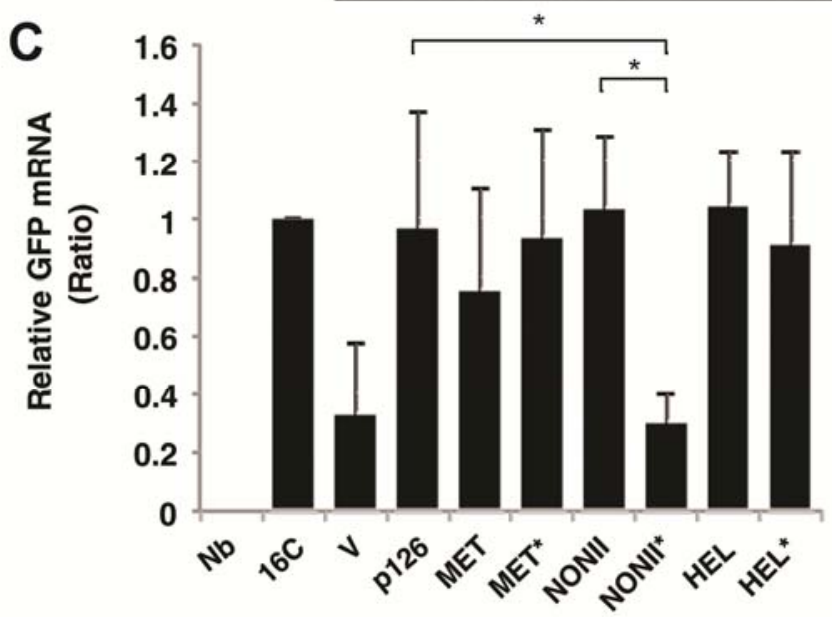

Fig. 5. Mutational analysis of the local RNA silencing-suppression activities of p126 domain mutants in Nicotiana benthamiana line $16 \mathrm{c}$ at 4 days postinoculation. A, Leaves were co-infiltrated with pBA-green fluorescent protein (GFP) and pBA empty vector (V), p126, or methyltransferase (MET*), nonconserved region (NONII*), or helicase (HEL*) mutants. White scale bars indicate $2 \mathrm{~cm}$. B, Northern blots showing accumulation levels of GFP mRNA and GFP small-interfering RNA (siRNA) in leaf patches infiltrated with various constructs. The GFP mRNA and siRNA levels in the 16c plants are set to 1.0 and those from the treated leaf tissues are expressed as relative values. Nb indicates samples from nontransgenic and noninfiltrated plants. rRNA and U6 RNA lanes serve as loading controls. C, Average levels (plus standard deviations) of GFP mRNA, based on data from three biological replicates, that were normalized to the endogenous GFP mRNA of $16 \mathrm{c}$ line. Statistical differences between p126 domains and vector clone are shown at $P<0.05(*)$. 
(strain C58C1 was selected with kanamycin/tetracycline and strain ABI, kanamycin/spectinomycin) (Sigma, St. Louis). The overnight culture $(1 \mathrm{ml})$ was inoculated into an LB medium supplemented with appropriate antibiotics, $10 \mathrm{mM}$ MES $(\mathrm{pH}$ 5.7), and $20 \mu \mathrm{M}$ acetosyringone (Voinnet et al. 2003) in a flask for further overnight growth at $28^{\circ} \mathrm{C}$ on a shaker $(250 \mathrm{rpm})$. After centrifugation, the bacteria were resuspended in a solution containing $10 \mathrm{mM} \mathrm{MgCl} 2,10 \mathrm{mM}$ MES (pH 5.7), and $100 \mu \mathrm{M}$ acetosyringone and left at room temperature for 2 to $3 \mathrm{~h}$ or overnight before being used for leaf infiltration. For co-infiltrations, equal volumes of both agrobacterial cultures with same density (optical density at $600 \mathrm{~nm}=1$ ) were mixed (Voinnet et al. 2000) and injected into leaves with a $1-\mathrm{ml}$ needless syringe. The infiltrated plants were kept at $22^{\circ} \mathrm{C}$ on the first day to facilitate trans-
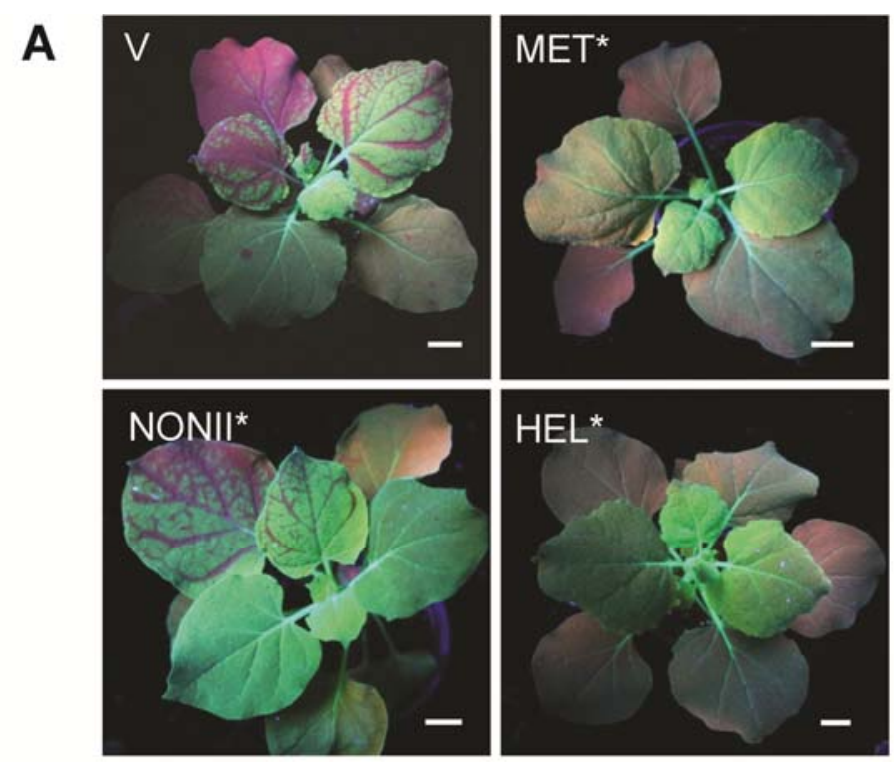

B

16c-GFP
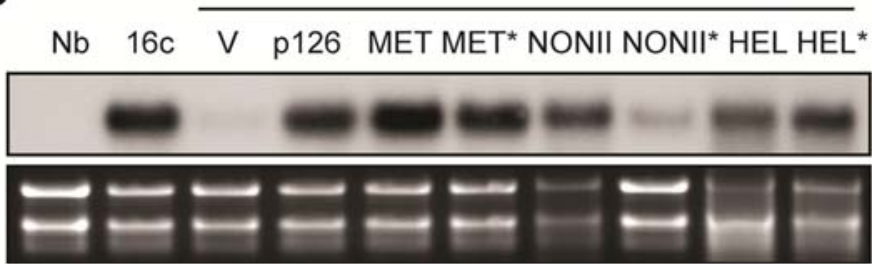

GFP mRNA

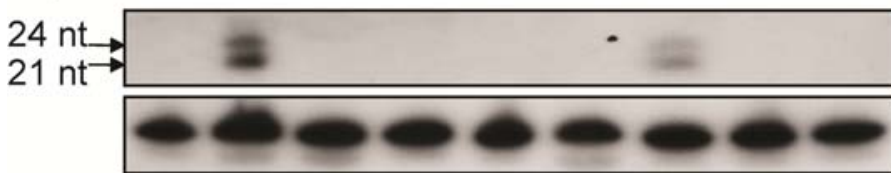

rRNA

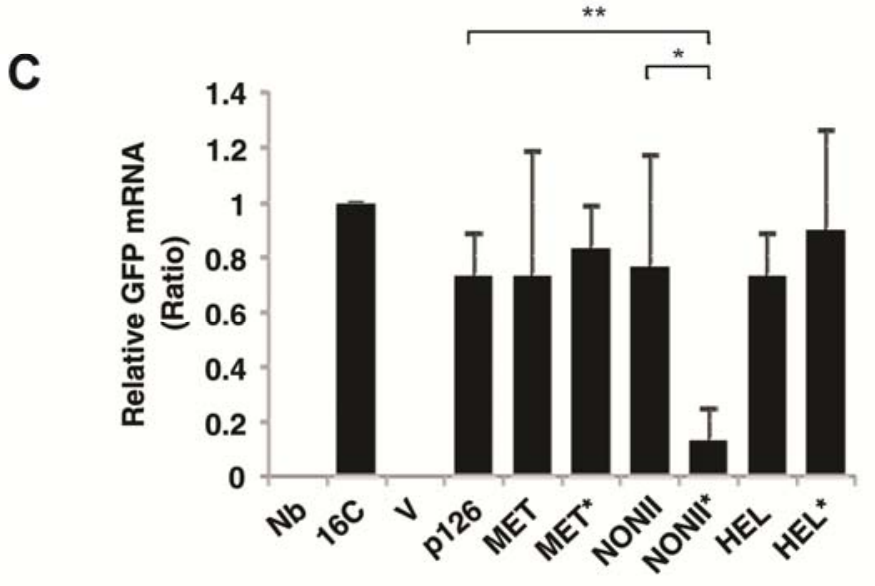

GFP SiRNA

U6

Fig. 6. Systemic RNA silencing-suppression activities of p126 domain mutants in Nicotiana benthamiana line 16c at 18 days postinoculation. A, Systemic leaves from plants co-infiltrated with pBA-green fluorescent protein (GFP) and pBA empty vector (V), p126, or methyltransferase (MET*), nonconserved region (NONII*), or helicase (HEL*) mutants. White scale bars indicate $2 \mathrm{~cm}$. B, Northern blots showing accumulation levels of GFP mRNA and GFP small-interfering RNA (siRNA) in the systemic leaves. The GFP mRNA and siRNA levels in the 16c plants are set to 1.0 and those from the leaves of treated plants are expressed as relative values. $\mathrm{Nb}$ indicates samples from nontransgenic and noninfiltrated plants. rRNA and U6 RNA lanes serve as loading controls. C, Average levels (plus standard deviations) of GFP mRNA, based on data from three biological replicates, that were normalized to the endogenous GFP mRNA of 16c line. Statistical differences between p126 domains and vector clone are shown at $P<0.05$ and 0.01 levels (* and **, respectively). 
formation and then moved to a growth chamber at $24^{\circ} \mathrm{C}$ under the cycle of $16 \mathrm{~h}$ of light and $8 \mathrm{~h}$ of darkness.

\section{GFP fluorescence imaging.}

GFP fluorescence in agroinfiltrated plants was visualized under a portable UV lamp with a wavelength at $365 \mathrm{~nm}$ (UVP model UVGL-25, Upland, CA, U.S.A.) and photographed with a digital camera (approximately 18 to $55 \mathrm{~mm}$, EOS 350D; Cannon) using a UV filter (Fujiyama $58 \mathrm{~mm}$ ).

\section{Western blotting.}

Leaf tissues of agroinfiltrated $N$. benthamiana line $16 \mathrm{c}$ were grounded in liquid nitrogen with extraction buffer $(50 \mathrm{mM}$ Tris- $\mathrm{HCl}, \mathrm{pH} 8.0 ; 150 \mathrm{mM} \mathrm{NaCl} ; 10 \mathrm{mM}$ sodium fluoride; 0.1
$\mathrm{mM}$ sodium vanadate; $1 \mathrm{mM}$ benzamidine; $0.1 \%$ Triton $\mathrm{X}-100$; $1 \mathrm{mM}$ phenylmethylsulfonyl fluoride; aprotinin at $10 \mathrm{mg} / \mathrm{ml}$; and leupeptin at $20 \mathrm{mg} / \mathrm{ml}$ ) at a ratio of $1: 3(\mathrm{wt} / \mathrm{vol})$ of plant material to buffer. Total lysates were cleared by centrifugation at $13,000 \mathrm{rpm}$ for $30 \mathrm{~min}$ at $4^{\circ} \mathrm{C}$. The protein concentration was determined by Bradford protein assay (Sigma). Pull-down was performed by incubating the cell lysates with Ni-NTA agarose bead (Qiagen, Hilden, Germany) and mixed by gentle rotation at $4{ }^{\circ} \mathrm{C}$. Proteins separated on a $10 \%$ sodium dodecyl sulfate (SDS) polyacrylamide gel electrophorersis gel were electrophoretically transferred to nitrocellulose membranes (Schleicher \& Schuell BioScience, Dassel, Germany) with a transfer buffer (25 mM Tris base, $192 \mathrm{mM}$ glycine, and 20\% [vol/vol] methanol). The membranes were blocked with $5 \%$ (wt/vol) nonfat
A a
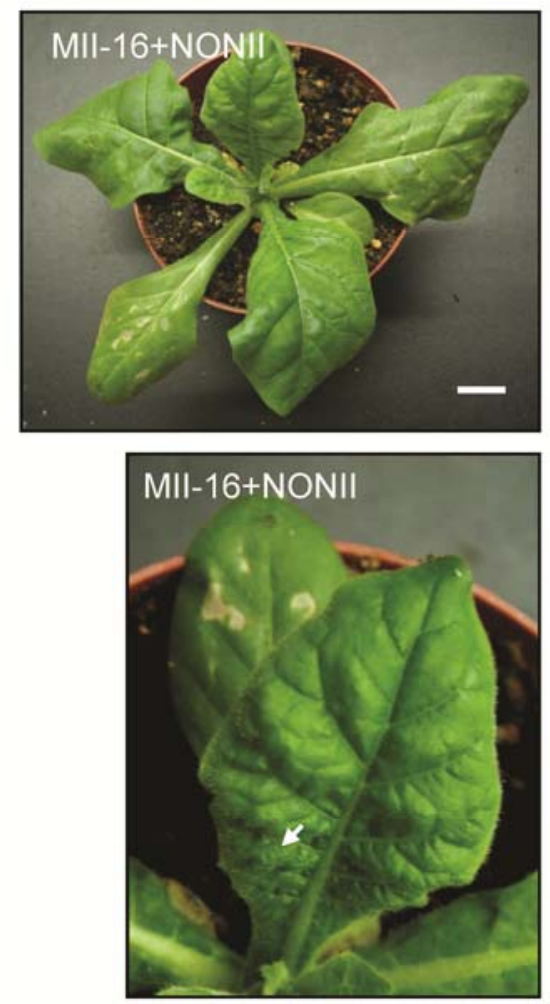

B

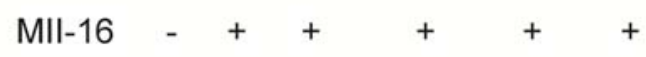

b
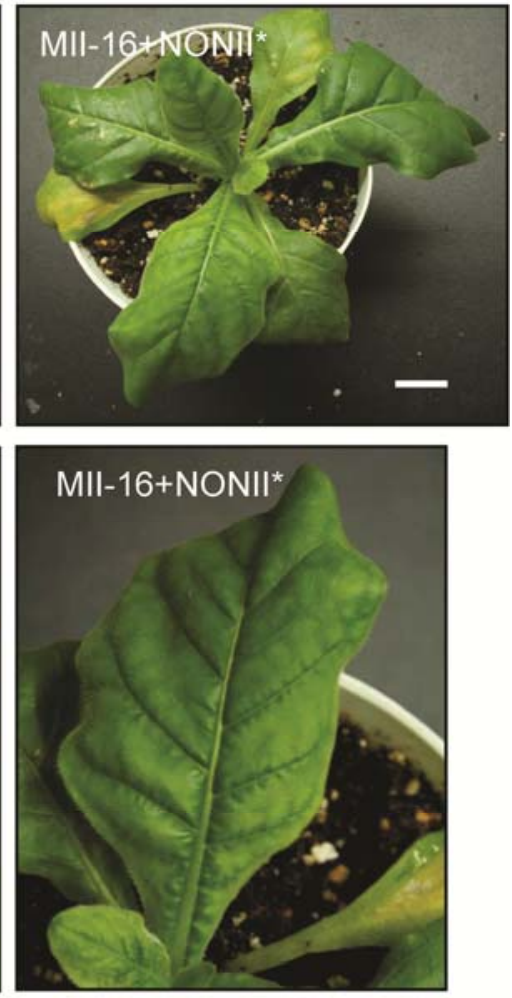

$+$

\section{Mock V NONII NONII* p126 NONI}

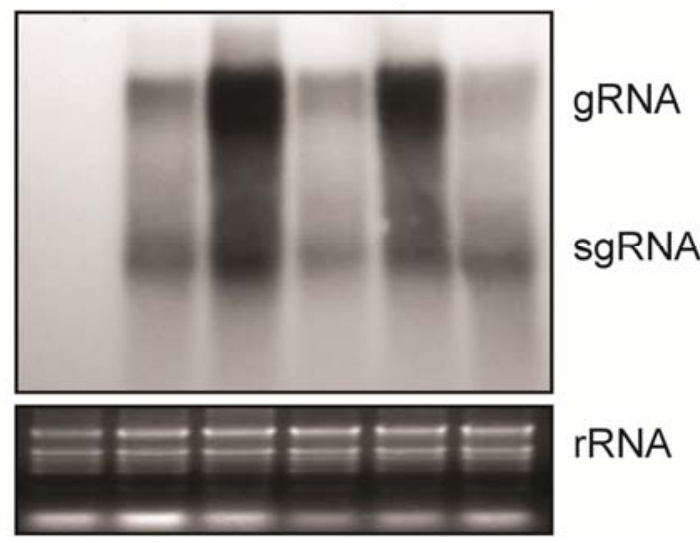

Fig. 7. Effects of nonconserved (NONII) and mutant form (NONI*) on symptom severity and Tobacco mosaic virus (TMV) accumulation in infected Nicotiana tabacum plants. A, Symptoms of $N$. tabacum plants infected with TMV MII-16 (mild strain) in the presence of NONII or NONII* at 11 days postinoculation (dpi); a, Symptoms of a plant infected with MII-16 plus NONII and b, symptoms of a plant infected with MII-16 and NONII*. B, Northern blot with TMV coat protein-specific probes showing accumulation levels of TMV genomic and subgenomic RNAs in systemic leaves at 7 dpi. 
Table 3. Primer sequences used for mutagenesis, reverse-transcriptase polymerase chain reaction and Northern (listed $5^{\prime}$ to $3{ }^{\prime}$ end)

\begin{tabular}{|c|c|}
\hline Primer $^{\mathrm{a}}$ & Sequence $^{b}$ \\
\hline $126-5^{\prime}$ & CCGCGGCCGCATGGCATACACACAGACAGC \\
\hline $126-3^{\prime}$ & GGCTCGAGGGATTGTGTTCCTGCATCGACC \\
\hline MET-3' & GGCTCGAGGTAAACCTCTCTATTAGAGGCCGG \\
\hline NONI-5' & CCGCGGCCGCATGAAGGAGTTTTTAGTCACCAG \\
\hline NONI-3' & GGETCGAGGGACAAGGATTGTAAAG \\
\hline NONII-5' & CCECGGCCGCATGACGTTTTACCTGCATACTAAG \\
\hline NONII-3' & GGCTCGAGGTCGGAATAAACAACAGCCTCAGAGC \\
\hline HEL-5' & CCGCGGCCGCATGGCGAAACTCAGAACTCTGCGCAGA \\
\hline Met $^{*}\left(\mathrm{His}^{81} \rightarrow\right.$ Ala $)$ sense & CGCAAAATGCCGTGgcTTCGCTTGCAGGTGG \\
\hline Met* $\left(\right.$ His $^{81} \rightarrow$ Ala $)$ antisense & CCACCTGCAAGCGA $\underline{\text { AgcCACGGCATTTTGCG }}$ \\
\hline nonII*602 (Glu ${ }^{602} \rightarrow$ Lys $)$ sense & CGGTCATGAGCAATaAGAGCGGTCTGACTC \\
\hline nonII*602 $\left(\mathrm{Glu}^{602} \rightarrow\right.$ Lys $)$ antisense & GAGTCAGACCGCTCTtATTGCTCATGACCG \\
\hline nonII*669 (Lys ${ }^{669} \rightarrow$ Arg) sense & CGTCCTATTCTㅁgAACGAGGAG \\
\hline nonII*669 $\left(\right.$ Lys $^{669} \rightarrow$ Arg) antisense & CTCCTCGTTCcgAGAATAGGACG \\
\hline nonII*747 $\left(\mathrm{Ala}^{747} \rightarrow \mathrm{Thr}\right)$ sense & GGAGTCTTGGATGTTaCATCTAGGAAGTGG \\
\hline nonII $* 747\left(\mathrm{Ala}^{747} \rightarrow \mathrm{Thr}\right)$ antisense & CCACTTCCTAGATGtAACATCCAAGACTCC \\
\hline $\mathrm{Hel}^{*}\left(\mathrm{Thr}^{840} \rightarrow\right.$ Ala $)$ sense & CCGGGCTGTGGGAAAgCCAAAGAAATTCTTTCC \\
\hline $\mathrm{Hel}^{*}\left(\mathrm{Thr}^{840} \rightarrow\right.$ Ala $)$ antisense & 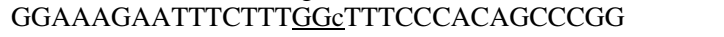 \\
\hline GFP-5' & ATGAAGACTAATCTTTTTCTCTTTCTCATC \\
\hline GFP-3' & TTAAAGCTCCATATGTTTGTATAGTTCATC \\
\hline
\end{tabular}

${ }^{a}$ MET = methyltransferase, NONI and NONII = two nonconserved regions, HEL = helicase, and GFP = green fluorescent protein.

${ }^{\mathrm{b}}$ Mutant sites are underlined and modified nucleotides are lowercase.

milk and $0.1 \%$ (wt/vol) bovine serum albumin containing Trisbuffered saline with Twee, $(50 \mathrm{mM}$ Tris- $\mathrm{HCl}, \mathrm{pH} 7.4 ; 150 \mathrm{mM}$ $\mathrm{NaCl}$; and $0.05 \%$ Tween 20). After buffer washes, the membranes were incubated with anti-myc monoclonal antibodies (9E10) followed by incubation with horseradish peroxidaseconjugated anti-mouse antibodies and ECL detection (Amersham, Bucks, U.K.).

\section{Reverse-transcriptase PCR.}

Approximately $0.5 \mathrm{~g}$ of $N$. benthamiana line $16 \mathrm{c}$ leaf tissues was ground to fine powders in liquid nitrogen. Total RNAs were extracted by TRIzol Reagent (Invitrogen) according to the manufacturer's instructions. The first-strand cDNAs were synthesized from $1 \mu \mathrm{g}$ of total RNA with a standard protocol (Superscript III reverse transcriptase; Invitrogen). Afterward, the cDNA products were amplified by PCR (Taq DNA polymerase; Invitrogen). These reactions were carried out in a Mycycler thermal cycle (Bio-Rad). The resulting PCR products were analyzed by electrophoresis on a $1 \%$ agarose gel and detected by ethidium bromide staining. The primer pair GFP-5' and GFP-3' was used to detect the expression of GFP mRNAs (Table 3). Elongation factor- $1 \alpha$ was used as an internal control (Ding et al. 2004).

\section{Northern blotting.}

GFP-specific probes were labeled by $\alpha-\left[{ }^{32} p\right]-d C T P$ using a random prime labeling system (GE Healthcare Life Sciences). U6 snRNA-specific probes were labeled by $\gamma-\left[{ }^{32} \mathrm{p}\right]$-ATP using T4 polynucleotide kinase (New England Biolabs, Beverly, MA, U.S.A.) followed by Mini Quick Spin oligo columns (Roche Diagnostics, Mannheim, Germany) purification. To prepare RNA samples for Northern blotting, RNA (4 to $5 \mu \mathrm{g})$ isolated from leaf tissues was electrophoresed on a $1.2 \%$ agarose gel with voltage of approximately 3 to $7 \mathrm{~V} / \mathrm{cm}$ in a running buffer of $10 \mathrm{mM}$ sodium phosphate $(\mathrm{pH} \mathrm{6.8)}$ and transferred onto Hybond- $\mathrm{N}^{+}$membranes (GE Healthcare Life Sciences, Piscataway, NJ, U.S.A.) with 2 to $10 \times \mathrm{SSC}(1 \times \mathrm{SSC}$ is $0.15 \mathrm{M}$ $\mathrm{NaCl}$ plus $0.015 \mathrm{M}$ sodium citrate). For analysis of siRNAs, 10 $\mu \mathrm{g}$ of the total RNA was loaded into each well in the Bio-Rad Protean IV minigel system (Bio-Rad) for electrophoresis in a 8 $\mathrm{M}$ urea per $15 \%$ polyacrylamide gel (19:1) (Amersco and Applichem, Darmstadt, Germany). The RNA was transferred onto Hybond- $\mathrm{N}^{+}$membranes in $1 \times$ Tris-borate-EDTA. The mem- branes were UV treated (120 mjoules) twice. After prehybridization in Utrahyb-oligo solution (Ambion, Inc., Austin, TX, U.S.A.) at $42^{\circ} \mathrm{C}$ for $1 \mathrm{~h}$, the membranes were hybridized with GFP-specific probes or with U6 snRNA-specific probes as an internal control. After hybridization at $42^{\circ} \mathrm{C}$ overnight, the membranes were washed by a buffer containing $2 \times$ SSC in $0.5 \%$ SDS and exposed on X-ray films (Super RX Medical XRay Film, FujiFilm, Tokyo). Band intensities were measured with Image J software.

\section{ACKNOWLEDGMENTS}

We thank M.-C. Chang and S.-M. Wang and Y.-W. Liu for excellent technical assistance and critical comments, and D. Baulcombe for providing $N$. benthamiana line $16 \mathrm{c}$. This study was supported by grants from the National Council of Science, Taiwan to T.-L. Shen (96-2313-B-002-059MY3 and 100-2321-B-002-033-MY3).

\section{LITERATURE CITED}

Anandalakshmi, R., Pruss, G. J., Ge, X., Marathe, R., Mallory, A. C., Smith, T. H., and Vance, V. B. 1998. A viral suppressor of gene silencing in plants. Proc. Natl. Acad. Sci. U.S.A. 95:13079-13084.

Aoyama, T., and Chua, N. H. 1997. A glucocorticoid-mediated transcriptional induction system in transgenic plants. Plant J. 11:605-612.

Bao, Y., Carter, S. A., and Nelson, R. S. 1996. The 126- and 183-kilodalton proteins of tobacco mosaic virus, and not their common nucleotide sequence, control mosaic symptom formation in tobacco. J. Virol. 70:6378-6383

Boutet, S., Vazquez, F., Liu, J., Beclin, C., Fagard, M., Gratias, A., Morel, J. B., Crete, P., Chen, X., and Vaucheret, H. 2003. Arabidopsis HEN1: a genetic link between endogenous miRNA controlling development and siRNA controlling transgene silencing and virus resistance. Curr. Biol. 13:843-848.

Brigneti, G., Voinnet, O., Li, W. X., Ji, L. H., Ding, S. W., and Baulcombe, D. C. 1998. Viral pathogenicity determinants are suppressors of transgene silencing in Nicotiana benthamiana. EMBO (Eur. Mol. Biol. Organ.) J. 17:6739-6746.

Dalmay, T., Horsefield, R., Braunstein, T. H., and Baulcombe, D. C. 2001. SDE3 encodes an RNA helicase required for post-transcriptional gene silencing in Arabidopsis. EMBO (Eur. Mol. Biol. Organ.) J. 20:20692078

Dawson, W. O., Beck, D. L., Knorr, D. A., and Grantham, G. L. 1986. cDNA cloning of the complete genome of tobacco mosaic virus and production of infectious transcripts. Proc. Natl. Acad. Sci. U.S.A. 83:1832-1836.

Derrick, P. M., Carter S. A. , and Nelson R. S. 1997. Mutation of the tobacco mosaic tobamovirus 126-and 183-kDa proteins: effects on phloem-dependent virus accumulation and synthesis of viral proteins. Mol. Plant- 
Microbe Interact. 10:589-596.

Diaz-Pendon, J. A., and Ding, S. W. 2008. Direct and indirect roles of viral suppressors of RNA silencing in pathogenesis. Annu. Rev. Phytopathol. 46:303-326.

Ding, S. W., and Voinnet, O. 2007. Antiviral immunity directed by small RNAs. Cell 130:413-426.

Ding, X. S., Liu, J., Cheng, N. H., Folimonov, A., Hou, Y. M., Bao, Y. Katagi, C., Carter, S. A., and Nelson, R. S. 2004. The Tobacco mosaic virus $126-\mathrm{kDa}$ protein associated with virus replication and movement suppresses RNA silencing. Mol. Plant-Microbe Interact. 17:583-592.

Erickson, F. L., Holzberg, S., Calderon-Urrea, A., Handley, V., Axtell, M., Corr, C., and Baker, B. 1999. The helicase domain of the TMV replicase proteins induces the $\mathrm{N}$-mediated defence response in tobacco. Plant J. 18:67-75.

Giner, A., Lakatos, L., Garcia-Chapa, M., Lopez-Moya, J. J., and Burgyan, J. 2010. Viral protein inhibits RISC activity by argonaute binding through conserved WG/GW motifs. PLoS Pathog. 6:e1000996.

Goregaoker, S. P., and Culver, J. N. 2003. Oligomerization and activity of the helicase domain of the Tobacco mosaic virus 126- and 183-kilodalton replicase proteins. J. Virol. 77:3549-3556.

Goregaoker, S. P., Lewandowski, D. J., and Culver, J. N. 2001. Identification and functional analysis of an interaction between domains of the 126/183-kDa replicase-associated proteins of Tobacco mosaic virus. Virology 282:320-328.

Harries, P. A., Palanichelvam, K., Bhat, S., and Nelson, R. S. 2008 Tobacco mosaic virus $126-\mathrm{kDa}$ protein increases the susceptibility of Nicotiana tabacum to other viruses and its dosage affects virus-induced gene silencing. Mol. Plant-Microbe Interact. 21:1539-1548.

Haseloff, J., Siemering, K. R., Prasher, D. C., and Hodge, S. 1997. Removal of a cryptic intron and subcellular localization of green fluorescent protein are required to mark transgenic Arabidopsis plants brightly. Proc. Natl. Acad. Sci. U.S.A. 94:2122-2127.

Holt, C. A., Hodgson, R. A., Coker, F. A., Beachy, R. N., and Nelson, R. S. 1990. Characterization of the masked strain of tobacco mosaic virus: identification of the region responsible for symptom attenuation by analysis of an infectious cDNA clone. Mol. Plant-Microbe Interact. 3:417-423.

Horwich, M. D., Li, C., Matranga, C., Vagin, V., Farley, G., Wang, P., and Zamore, P. D. 2007. The Drosophila RNA methyltransferase, DmHen1, modifies germline piRNAs and single-stranded siRNAs in RISC. Curr. Biol. 17:1265-1272

Jin, H., and Zhu, J. K. 2010. A viral suppressor protein inhibits host RNA silencing by hooking up with Argonautes. Genes Dev. 24:853-856.

Kadare, G., and Haenni, A. L. 1997. Virus-encoded RNA helicases. J. Virol. 71:2583-2590.

Kasschau, K. D., and Carrington, J. C. 1998. A counterdefensive strategy of plant viruses: suppression of posttranscriptional gene silencing. Cell 95:461-470

Knapp, E., Danyluk, G. M., Achor, D., and Lewandowski, D. J. 2005. A bipartite Tobacco mosaic virus -defective RNA (dRNA) system to study the role of the N-terminal methyl transferase domain in cell-to-cell movement of dRNAs. Virology 341:47-58.

Koonin, E. V., and Dolja, V. V. 1993. Evolution and taxonomy of positivestrand RNA viruses: implications of comparative analysis of amino acid sequences. Crit. Rev. Biochem. Mol. Biol. 28:375-430.

Lewandowski, D. J., and Dawson, W. O. 1993. A single amino acid change in tobacco mosaic virus replicase prevents symptom production. Mol. Plant-Microbe Interact. 6:157-160.

Li, J., Yang, Z., Yu, B., Liu, J., and Chen, X. 2005. Methylation protects miRNAs and siRNAs from a 3'-end uridylation activity in Arabidopsis. Curr. Biol. 15:1501-1507.

Liu, J. Z., Blancaflor, E. B., and Nelson, R. S. 2005. The Tobacco mosaic virus 126-kilodalton protein, a constituent of the virus replication complex, alone or within the complex aligns with and traffics along microfilaments. Plant Physiol. 138:1853-1865.

Martin-Hernandez, A. M., and Baulcombe, D. C. 2008. Tobacco rattle virus 16-kilodalton protein encodes a suppressor of RNA silencing that allows transient viral entry in meristems. J. Virol. 82:4064-4071.

Merai, Z., Kerenyi, Z., Kertesz, S., Magna, M., Lakatos, L., and Silhavy, D. 2006. Double-stranded RNA binding may be a general plant RNA viral strategy to suppress RNA silencing. J. Virol. 80:5747-5756.

Merits, A., Kettunen, R., Makinen, K., Lampio, A., Auvinen, P., Kaariainen, L., and Ahola, T. 1999. Virus-specific capping of tobacco mosaic virus RNA: methylation of GTP prior to formation of covalent complex p126m7GMP. FEBS (Fed. Eur. Biochem. Soc.) Lett. 455:45-48.

Osman, T. A., and Buck, K. W. 1997. The tobacco mosaic virus RNA polymerase complex contains a plant protein related to the RNA-binding subunit of yeast eIF-3. J. Virol. 71:6075-6082.

Pantaleo, V., Szittya, G., and Burgyan, J. 2007. Molecular bases of viral RNA targeting by viral small interfering RNA-programmed RISC. J. Virol. 81:3797-3806.

Park, W., Li, J., Song, R., Messing, J., and Chen, X. 2002. CARPEL FACTORY, a Dicer homolog, and HEN1, a novel protein, act in microRNA metabolism in Arabidopsis thaliana. Curr. Biol. 12:1484-1495.

Pelle, R., and Murphy, N. B. 1993. Northern hybridization: rapid and simple electrophoretic conditions. Nucleic Acids Res. 21:2783-2784.

Popova, B., Kuhlmann, M., Hinas, A., Soderbom, F., and Nellen, W. 2006. HelF, a putative RNA helicase acts as a nuclear suppressor of RNAi but not antisense mediated gene silencing. Nucleic Acids Res. 34:773-784.

Rast, A. T. B. 1972. MII-16, an artificial symptomless mutant of tobacco mosaic virus for seedling inoculation of tomato crops. Eur. J. Plant Pathol. 78:110-112.

Ruiz, M. T., Voinnet, O., and Baulcombe, D. C. 1998. Initiation and maintenance of virus-induced gene silencing. Plant Cell 10:937-946.

Shintaku, M. H., Carter, S. A., Bao, Y., and Nelson, R. S. 1996. Mapping nucleotides in the $126-\mathrm{kDa}$ protein gene that control the differential symptoms induced by two strains of tobacco mosaic virus. Virology 221:218-225

Taylor, D. N., and Carr, J. P. 2000. The GCD10 subunit of yeast eIF-3 binds the methyltransferase-like domain of the 126 and $183 \mathrm{kDa}$ replicase proteins of Tobacco mosaic virus in the yeast two-hybrid system. J. Gen. Virol. 81:1587-1591.

Vaistij, F. E., Jones, L., and Baulcombe, D. C. 2002. Spreading of RNA targeting and DNA methylation in RNA silencing requires transcription of the target gene and a putative RNA-dependent RNA polymerase. Plant Cell 14:857-867.

Vaucheret, H. 2006. Post-transcriptional small RNA pathways in plants: mechanisms and regulations. Genes Dev. 20:759-771.

Voinnet, O. 2005. Induction and suppression of RNA silencing: insights from viral infections. Nat. Rev. Genet. 6:206-220.

Voinnet, O., and Baulcombe, D.C. 1997. Systemic signalling in gene silencing. Nature 389:553.

Voinnet, O., Pinto, Y. M., and Baulcombe, D. C. 1999. Suppression of gene silencing: a general strategy used by diverse DNA and RNA viruses of plants. Proc. Natl. Acad. Sci. U.S.A. 96:14147-14152.

Voinnet, O., Lederer, C., and Baulcombe, D. C. 2000. A viral movement protein prevents spread of the gene silencing signal in Nicotiana benthamiana. Cell 103:157-167.

Voinnet, O., Rivas, S., Mestre, P., and Baulcombe, D. 2003. An enhanced transient expression system in plants based on suppression of gene silencing by the p19 protein of Tomato bushy stunt virus. Plant J. 33:949956.

Yamaji, Y., Kobayashi, T., Hamada, K., Sakurai, K., Yoshii, A., Suzuki, M., Namba, S., and Hibi, T. 2006. In vivo interaction between Tobacco mosaic virus RNA-dependent RNA polymerase and host translation elongation factor 1A. Virology 347:100-108.

Yu, B., Yang, Z., Li, J., Minakhina, S., Yang, M., Padgett, R. W., Steward, R., and Chen, X. 2005. Methylation as a crucial step in plant microRNA biogenesis. Science 307:932-935.

Zhang, X., Garreton, V., and Chua, N. H. 2005. The AIP2 E3 ligase acts as a novel negative regulator of ABA signaling by promoting $\mathrm{ABI} 3$ degradation. Genes Dev. 19:1532-1543. 